\title{
Penggunaan Media Spinning Wheel Dalam Pembelajaran Qawaid Nahwu
}

\author{
Nisa Fahmi Huda \\ Universitas Islam Negeri Sunan Kalijaga Yogyakarta \\ nisafahmi22@gmail.com
}

\author{
Article History: \\ Received: \\ 30 November 2020 \\ Revised: \\ 16 Desember 2020 \\ Accepted: \\ 30 Desember 2020
}

\section{Keywords:}

Spinning Wheel Media, Qawaid

Nabwu

\begin{abstract}
:
It feels familiar to us with one of the Arabic subjects. Moreover, Arabic learning has existed at the school level from elementary to tertiary education. Arabic learning must stand and cannot be separated from several kinds of language skills, such as listening, speaking, reading, and writing. However, apart from the four language skills, we must pay attention to one of the important aspects of language and this is also not separated because without this aspect, language will not be organized. These important aspects are the nabwu rules that we must learn and cannot be separated from the four skills of Arabic. The purpose of this study was to determine how effective the use of the spinning wheel media was in learning Arabic, especially in the subject of qawaid nabwu. Data collection methods used observation, interviews, tests, and documentation. The approach used is quantitative with the type of research Quasi Experimental One Group Pretest Posttest. The result of this research is that the use of the spnning wheel media can improve the qawaid nabwu learning process in the seventh grade training of the students of the Darul Qur'an Wal Islamic Boarding School, Wonosari, Gunungkidul, Yogyakarta.
\end{abstract}

\section{Pendahuluan}

Bahasa Arab sangatlah penting untuk dipelajari, khususnya oleh umat Islam. Mempelajari bahasa Arab haruslah dengan mempelajari empat keterampilan bahasa atau biasa disebut dengan maharatul lughah. Akan tetapi selain mempelajari maharatul lughah ada lagi unsur yang sangat penting yang tidak boleh kita tinggalkan dalam mempelajari bahasa Arab yaitu dari unsur kaidahnya. Dalam bahasa Arab, kaidah nahwu menjadi bagian yang pokok dan penting untuk dipelajari. ${ }^{1}$

Sebagai salah satu ilmu yang krusial untuk dipelajari, ilmu nahwu tidak dapat ditinggalkan, jika diabaikan dan tidak dipelajari maka pembelajaran bahasa Arab terutama dari unsur kaidahnya akan menjadi berantakan dalam menyusun kata serta menjadikan sebuah kalimat tersebut tidak teratur.

Terkesan pembelajaran qawaid nabwu termasuk ilmu yang susah dimengerti apalagi untuk siswa pemula yang baru saja mengenal matei qawaid nabwu, padahal banyak metode, cara atau media sebagai sarana yang bisa digunakan oleh guru dalam mengajarkan pada siswa terutama siswa tingkat pemula. Kesan umum yang sering terdengar dari pembelajar bahasa Arab adalah bahwa

\footnotetext{
${ }^{1}$ Arif Rahman Hakim, “Mempermudah Pembelajaran Ilmu Nahwu Pada Abad 20,” Jurnal Al Maqayis 1, no. 1 (2014).
} 
mempelajari bahasa Arab itu sulit dan sangat membosankan, karena bahasa Arab bukanlah bahasa pertama bagi pembelajar di Indonesia ${ }^{2}$. Bahasa Arab sering kali dianggap sebagai “momok" (sesuatu yang menakutkan) bagi siswa, sehingga siswa menjadi tak acuh terhadap bahasa Arab, minim akan minat belajar dan akhirnya menjadi banyak siswa yang tidak tertarik mempelajari bahasa Arab

Mengacu pada sistem pendidikan, peran guru sebagai pengajar atau orang yang menyampaikan pesan-pesan dalam segi pendidikan sangat memerlukan alat bantu media agar proses dalam melaksanakan kegiatan pembelajaran dapat berlangsung secara efektif dan berhasil. Materi yang disajikan dalam pembelajaran pada pokok bahasan dengan menngunakan metode dan alat bantu media yang tepat akan membangkitkan gairah siswa dan mampu mengetuk semangat dan minat siswa untuk belajar sesuai materi yang telah disajikan oleh guru. Media adalah komponen sumber belajar atau sarana fisik yang mengandung materi instruksional di lingkungan peserta didik yang dapat merangsang peserta didik untuk belajar atau alat yang digunakan untuk menyampaikan atau mengantarkan pesan-pesan pembelajaran ${ }^{3}$.

Dari pengamatan penulis sesuai dari apa yang dilihat di lapangan bahwa hasil observasi dan wawancara dengan guru bahasa Arab, terdapat beberapa faktor mengapa masih banyak santriwati tingkat pemula khususnya pada kelas VII di Pondok Pesantren Darul Qur'an Wal Irsyad, Wonosari, Gunungkidul, Yogyakarta yang merasakan sulit dalam mempelajari qawaid nabwu. Hal ini dikarenakan penyampaian materi yang kurang komunikatif atau tidak bervariasi, metode atau cara dalam mengajar dirasa masih kurang tepat, kurangnya pemberian latihan secara berkelanjutan seperti mengubah kalimat-kalimat fi'liyyah menjadi ismiyyah, membuat contoh-contoh dasar, dan juga media belajar, dan buku-buku qawaid masih terlihat sedikit membosankan dengan bentuk tulisan yang masih kelihatan kecil-kecil, tidak diperlihatkan contoh gambar dan warna yang tidak menarik. Inilah yang membuat minat santriwati menurun dan malas untuk mempelajarinya. Tidak hanya peran guru dan metode belajar saja, tetapi peran alat bantu berupa media juga harus diperhatikan dalam mencapai proses suatu pembelajaran. Jika media yang digunakan hanya bahan ajar berupa buku, akan terlihat monoton, akan menjadikan santriwati kehilangan minat dan semangat belajar. Sehingga pembelajaran akan menjadi tidak maksimal.

Oleh karena itu alat bantu media merupakan bagian dari sistem yang sangat penting dalam mencapai proses pembelajaran yang akan memberikan hasil belajar peserta didik meningkat. Media spinning wheel dirasa sangat cocok untuk mencapai tujuan pembelajaran qawaid nahwu, yaitu dengan pemaparan teks kemudian disusul dengan contoh-contoh dan terakhir menjelaskan kaidah-kaidah.

\footnotetext{
2 Mochamad Hasyim and Amang Fathurrohman, "Pengembangan Desain Permainan Stik Lalaran Untuk Peningkatan Kemampuan Mufrodat Dalam Kitab Bahasa Arab Ro'sun Sirah Bagi Santri Madrasah Diniyah Tingkat Ula," Studi Arab 9, no. 2 (2018): 147-160.

3 Tejo Nurseto, "Membuat Media Pembelajaran Yang Menarik," Jurnal Ekonomi dan pendidikan 8, no. 1 (2011). Hal 21
} 
Media spinning wheel digunakan untuk menunjang soal dan latihan-latihan kepada siswa supaya peserta didik tidak cepat bosan saat guru mengajar di dalam kelas.

Melihat penelitian-penelitian sebelumnya seperti yang dilakukan oleh Neli Sa'adah mengenai "metode deduktif dengan menggunakan media kartu dalam memahami jumlah fi'liyyah" sangat berpengaruh dalam meningkatkan pemahaman mahasantri terkait materi nahwu khususnya, jumlah fi'liyah. Dengan kata lain, penerapan metode deduktif dengan menggunakan media kartu berpengaruh dalam meningkatkan pemahaman jumlah fi'liyah mahasantri ma'had Al Jami'ah IAIN Syekh Nurjati Cirebon tahun ajaran 2016/2017.

Penelitian yang dilakukan oleh Siti Nur Amalah mengenai “ penggunaan media papan lipat untuk meningkatkan penguasaan tata bahasa Arab (mubtada' Khabar) dan keterampilan membaca siswa kelas VII MTs Hasyimiyah Kalisidi Ungaran menunjukkan bahwa pembelajaran menggunakan media papan lipat efektif untuk penguasaan tata bahasa Arab dan keterampilan membaca siswa kelas VII MTs Hasyimiyah Kalisidi Ungaran".

Begitupun penelitian yang dilakukan oleh Riska Puspita Devi mengenai peningkatan hasil belajar qawaid bahasa arab melalui metode al-qawaid wa-tarjamah menggunakan media visual gambar bagi siswa kelas IV Kolomayan Wonodadi Blitar, menunjukkan hasil belajar yang meningkat. Melalui metode qawaid wa-tarjamah dan media visual gambar dapat meningkatkan hasil belajar siswa kelas IV MIN Kolomayan Wonodadi Blitar tahun ajaran 2013-20145.

Dari teori dan penelitian terdahulu yang telah dilakukan oleh peneliti, pembelajaran qawaid nabwu dengan menggunakan media game interaktif memiliki pengaruh yang positif dalam meningkatkan pembelajaran qawaid nabwu. Berdasarkan pentingnya pembelajaran materi qawaid nahwu, dan fakta di lapangan yang menunjukkan kendala dalam pembelajaran qawaid nabwu, penulis ingin mengetahui pengaruh hasil belajar peserta didik dengan penggunaan media pembelajaran media spinning wheel dalam pembelajaran bahasa Arab pada qawaid nahwu.

\section{Metode}

Penelitian yang dipakai peneliti adalah pendekatan kuantitaif, sedangkan jenis yang digunakan adalah penelitian quasi exsperimental. Penelitian ini adalah penelitian eksperimen yang dilakukan dalam satu kelompok saja ${ }^{6}$. Melaksanakan pretest terlebih dahulu kemudian diberi

\footnotetext{
${ }^{4}$ Siti Fitri Amalah, "EFEKTIVITAS MEDIA PAPAN LIPAT UNTUK PENINGKATAN PENGUASAAN TATA BAHASA ARAB (MUBTADA KHABAR) DAN KETERAMPILAN MEMBACA SISWA KELAS VII MTs HASYIMIYAH KALISIDI UNGARAN" (Universitas Negeri Semarang, 2017), https://docplayer.info/151793125-Skripsi-untuk-memperoleh-gelar-sarjana-pendidikan.html. ${ }^{5}$ Riska Puspita Devi, "PENINGKATAN HASIL BELAJAR BAHASA ARAB MELALUI METODE ALQAWAID WA-TARJAMAH MENGGUNAKAN MEDIA VISUAL GAMBAR BAGI SISWA KELAS IV MIN KOLOMAYAN WONODADI BLITAR” (Institut Agama Islam Negeri (IAIN) Tulungagung, 2014).

${ }^{6}$ Bambang Prasetyo and Lina Miftahul Jannah, "Metode Penelitian Kuantitatif: Teori Dan Aplikasi, Jakarta, PT," Raja Grafindo Persada (2006).
} 
perlakukan lalu setelahnya melakukan posttest untuk mengetahui hasil yang dilakukan oleh siswa meningkat atau tidak. Dengan demikian teknik dengan menggunakan penelitian eksperimen bisa dianggap sebagai teknik penelitian yang kegunaannya adalah untuk mencari hasil setelah menggunakan perlakuan itu dapat meningkat atau tidak.

\section{Populasi dan Sampel}

Populasi yang peneliti gunakan adalah adalah santriwati kelas VII Pondok Pesantren Darul Qur'an Wal Irsyad dengan jumlah santriwati sebanyak berjumlah 30 orang. Peneliti menggunakan sampel yaitu dengan menunjuk secara random dari keseluruhan populasi yang ada di kelas VII.

\section{Desain Penelitian}

Untuk desain penelitian ini, peneliti menggunakan one group pretest-posttest design, yaitu penelitian eksperimen tetapi hanya untuk satu kelompok atau satu kelas saja ${ }^{7}$. Desain dengan penelitian ini diukur melalui pretest dan posttest. Pretest sebelum diberikan perlakuan dan posttest seletah diberikan perlakuan. Dari pretest dan posttest kita dapat melihat hasil secara akurat. Tabel one group pretest-posttest design bisa dilihat sebagai berikut:

Tabel 2. one group pretest-posttest design

\begin{tabular}{|r|c|c|}
\hline Pretest & Treatment & Posttest \\
\hline$T_{1}$ & $\mathrm{X}$ & $T_{2}$ \\
\hline
\end{tabular}

$T_{1}$ : Tes awal (pretest) dilakukan sebelum pemberian treatment oleh peneliti.

$\mathrm{X}$ : Perlakuan (Treatment) yang diberikan kepada santriwati.

$T_{2}$ : tes akhir (posttest) dilakukan setelah pemberian treatment oleh peneliti.

\section{Teknik Pengumpulan Data}

Adapun teknik pengumpulan data yang dilakukan oleh peneliti adalah sebagai berikut:

1) Observasi

Observasi ini dilakukan untuk memantau proses selama pembelajaran antara guru dan siswa yang terjadi di lapngan yaitu di dalam kelas santriwati kelas VII Pondok Darul Qur'an Wal Irsyad.

2) Wawancara diperlukan untuk mengetahui proses pembelajaran qawaid nahwu yang dialami oleh guru dan santriwati, media dan metode yang digunakan beserta kendala-kendalanya, serta rspon siswa saat menggunakan media spinning wheel pada pembelajaran qawaid nabwu.

\footnotetext{
${ }^{7}$ Arifin Zainal, "Penelitian Pendidikan,” Bandung: Rosda (2012).
} 
3) Tes

Tes dilakukan untuk menguji peningkatan pembelajaran qawaid nahwu pada latihan soal pada materi yang telah diajarkan guru. Tes yang digunakan dalam penelitian ini menggunakan Pretest dan posttest. ${ }^{8}$ Pretest Dilakukan melaksanakan pembelajaran qawaid nahwu menggunakan media spinning wheel dan posttest dilakukan setelah pemberian treatmnent dari sini akan dilihat sejauh mana peningkatan pembelajaran qawaid nabwu.

4) Dokumentasi

Pengumpulan data dilakukan dengan mendokumentasikan kegiatan selama pembelajaran menggunakan media foto.

\section{Hasil dan Pembahasan}

\section{Pembelajaran Qawaid Nahwu}

Pembelajaran merupakan suatu proses dari lingkungan yang sudah diatur guna merubah perilaku peserta didik dari yang sebelumnya belum baik agar menjadi lebih baik sesuai dengan kadar kemampuan dan perbedaan peserta didik.

Qawa'id jama' dari kata kaidah yang berarti aturan. Jadi Qawa'id adalah kaidah yang sudah diatur untuk kemudian bisa digunakan dalam penyusunan kata atau kalimat dalam bahasa Arab. Dimana qawaid sini memiliki dua cabang yang biasa kita ketahui yaitu ilmu nabwu dan saraf. Dengan demikian, mempelajari qawa’id bisa diartikan sebagai proses yang dilalui peserta didik dengan cara berinteraksi dengan lingkungan sekitar. Dari situlah kita dapat mengatahui perilaku peserta siswa dan mereka bisa memahami, kemudian mengerti sehingga bisa menguasai ilmu qawaid yang diharapkan dapat menjembatani kemampuan meraka dalam berinteraksi dengan lawan bicara maupun dalam mempelajari bacaan secara baik dan benar.

Sedangkan ilmu nahwu secara bahasa adalah الطريق و الجهة (jalan dan arah). Akan tetapi menurut istilah, ilmu yang membahas tetang keadaan akhir suatu kalimat dari segi $i$ 'rab (perubahan bunyi akhir kata) dan bina' (ketetapan bunyinya). Secara singkat i'rab ialah mengetahui fungsi atau kedudukan kosakata dalam suatu kalimat ditinjau dari segi rafa', nashab, jazm, lalu mengetahui harakat-harakat i'rab nya dan kalimat-kalimat yang harakat akhirnya tetap (mabni) ${ }^{9}$.

Dapat disimpulkan bahwa definisi qawaid nahwu adalah suaty ilmu yang memiliki suatu aturan atau kaidah-kaidah bahasa arab tentang keadaan akhir suatu kalimat dari segi i’rab maupun bina'.

\footnotetext{
${ }^{8}$ Suharsimi Arikunto, "Prosedur Penelitian Suatu Pendekatan Praktik. 2010," Jakarta: Rineka Cipta (2010).

${ }^{9}$ Razin Abu Razin and Razin Ummu Razin, "Ilmu Nahwu Untuk Pemula” (Pustaka Bisa, 2014).
} 
Adapun tujuan dan manfaat yang kita dapat dalam belajar ilmu qawaid nabwu adalah:

a. Menhindari dari kesalahan dalam mengucapkan, menjaga kesalahan dalam menulis, akan terbiasa dalam berkomunkasi dan berbahasa dengan benar dan cepat.

b. Dapat membantu dalam memahami apa yang diucapkan dalam sebuah perkataan baik lisan maupun tulisan.

c. Membantu menguatkan alkal, menambah penguasaan koskaata bagi peserta didik.

d. Agar siswa memperoleh kemampuan dalam mengaplikasikan unsur kaidah nahwu ketika membuat kalimat yang berbeda-beda. Maka hasilya siswa dapat memperoleh pembelajaran yang mantap dalam mengaplikasikan kaidah-kaidah nahwu ketika diterapkan dalam kehidupan dan mempraktikkan kaidah-kaidah nahwu dengan memberikan contoh pada kalimat sederhana. Maka dari situ kita bisa melihat hasil pembelajaran peserta didik yang terlihat mantap dalam mempraktikkan kaidah nahwu serta akan lancar ketika digunakan dalam kehidupan sehari-hari maupun prakti lisan atau tulisan.

e. Membantu para peserta didik dalam memahami ungkapan-ungkapan bahasa Arab sehingga dapat lebih menguasai dan mempercepat daya pemahaman yang ada dalam pikiran mereka tentang maksud dari pembicaran yang berbahasa Arab $^{10}$.

\section{Media Spinning Wheel.}

Media spinning wheel menjadi sebuah media pembelajaran yang menjembatani dan memfasilitasi peserta dalam memecahkan sebuah persoalan dengan cara mengerjalan soal-soal latihan yang berhubungan dengan materi qawaid nahwu. Soal-soal latihan yang dirangkai dalam bentuk seperti roda dan dapat diputar. Masing-masing juring memiliki soal dan ada jarum penunjuknya. dimana jarum penunjuk ketika setelah berhenti maka pertanyaan jatuh pada soal yang ditunjuk oleh jarum penunjuk, dan peserta didik diwajibkan menyeslesaikan soal tersebut.

Paul Ginnis menjelaskan bahwa media spinning wheel merupakan media permainan yang memiliki kelebihan sangat menantang, dapat dapat mendorong peserta didik untuk menyelesaikan soal-soal latihan secara berkelanjutan melalui juring yang setiap juringnya diberi soal ${ }^{11}$. Seperti yang dikatakan juga oleh Jhon Dabell bahwa media spinning wheel merupakan suatu media yang yang menitikberatkan pada aktivitas untuk mendorong peserta didik dengan kemampuan visualisasinya dalam menjawab soal dan spinning wheel ini dapat dilakukan oleh individu maupun kelompok dalam jumlah besar.

Dari pendapat yang disampaikan di atas, dapat dapat sisimpulkan bahwa media pembelajaran spinning wheel merupakan media yang melibatkan siswa untuk ikut serta dalam

\footnotetext{
10 Talqis Nurdianto, Ilmu Nahwu Bahasa Arab (Yogyakarta: Zahir Publishing, 2018).

${ }^{11}$ Paul Ginnis, Trik Dan Taktik. Mengajar: Strategi Meningkatkan Pencapaian Pengajaran Di Kelas (Jakarta: PT Indexs, 2008).
} 
memecahkan permasalahan yaitu berupa soal-soal latihan dalam pembelajaran qawaid nabwu yang telah disajikan oleh guru.

Media spinning wheel ini memiliki 10 juring. Pada setiap juring terdapat kartu pertanyaan yang telah dibuat oleh guru. Guru atau siswa dapat memutar media spinning wheel dan bagian juring yang berhenti dapat langsung dibuka oleh peserta didik mengenai soal latihan yang harus dikerjakan. Siswa diminta membuka kertas yang di dalamnya terdapat beberapa pertanyaan dan dipersilahkan untuk menjawab pertanyaan tersebut, jika siswa berhasil menjawab pertanyaan dengan tepat, maka skor yang diberikan oleh guru 100, apabila jawaban kurang tepat maka guru akan memberikan skor setengahnya, tetapi jika jawaban tidak ada yang benar maka skor yang diberikan 0 .

Keunggulan dan kelemahan media spinning whell:

1. Peserta didik dititikberatkan pada kegiatan belajar sehingga daya serap akan pengetahuan benar-benar dapat dipahami dan diserap dengan baik

2. peserta didik dilatih untuk bisa bekerja sama.

3. peserta didik dilatih pemahamannya dalam menjawab soal-soal latihan, karena dengan hal itu minat belajar peserta didik akan bertambah.

4. Merupakan permainan dengan dengan kelebihan yang bisa membuat menantang, seperti banyak permainan yang kita tahu di media televisi. Jenis media ini sudah banyak orang tahu.

5. Dapat dijadikan sebagai persiapan sebelum melaksanakan ujian pembelajaran yang bisa dipersiapkan sebaik dan semenarik mungkin.

Kelemahan media spinning wheel:

1. Untuk siswa yang enggan belajar atau belum terpacu semangatnya maka dirasa media ini tidak dapat mencapai pembelajaran yang maksimal baik dari segi materi maupun latihan soal.

2. Membutuhkan manajemen waktu yang pas $^{12}$.

Langkah-langkah dalam menggunakan media spinning wheel sebagai berikut:

1. Guru menyajikan materi pembelajaran.

2. Guru menerangkan materi pembelajaran kepada peserta didik.

3. Peserta didik dibagi menjadi beberapa kelompok atau bisa juga secara individu.

4. Guru meletakkan media spinning wheel dengan cara digantungkan atau dengan penyanggah.

5. Guru atau siswa memutar media spinning wheel hingga berhenti dan jarum penunjuk menunjukkan pada bagian juring yang terpilih kemudian, guru memberi arahan kepada peserta didik untuk membacakan latihan soal di depan kelas.

${ }^{12}$ John Dabell, “Aktivitas Permainan Dan Ide Praktis Belajar Matematika," Jakarta: Erlangga (2009). 
6. Guru mengarahkan peserta didik untuk mengerjakan soal-soal latihan qawaid nahwu yang sudah tersedia dalam kertas pertanyaan.

7. Guru mengoreksi kembali hasil latihan yang dikerjakan peserta didik secara bersama-sama.

8. Point terbesar dari hasil nilai yang dikerjakan peserta didik secara kelompok maupun individu akan mendapatlan hadiah dari guru sesuai dengan kesepakatan antara guru dan peserta didik.

\section{Pembelajaran Qawaid Nahwu Menggunakan Media Spinning Whell}
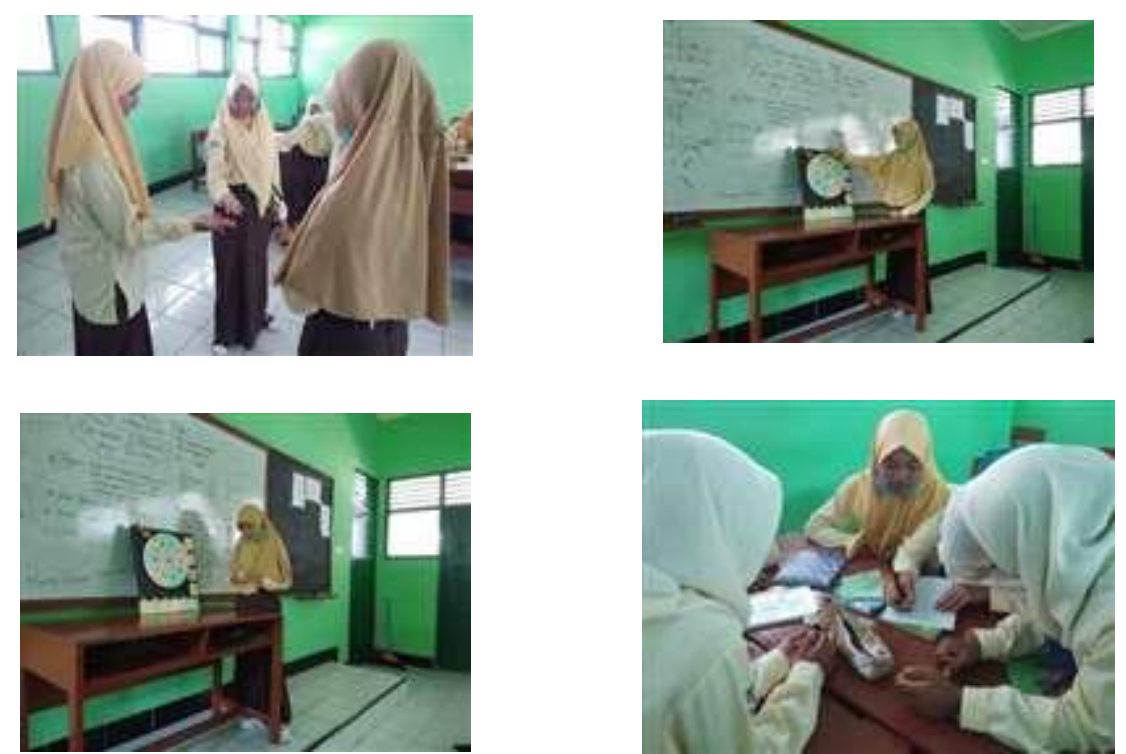

Gambar 1. Pembelajaran Qawaid Nabwu Menggunakan Media Spinning Whell

Tabel 1. Desain Media Spinning Wheel

Media Spinning Wheel

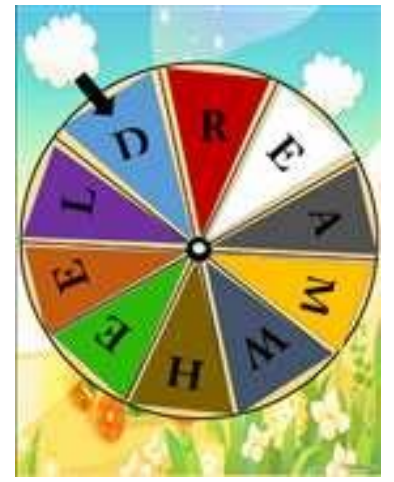




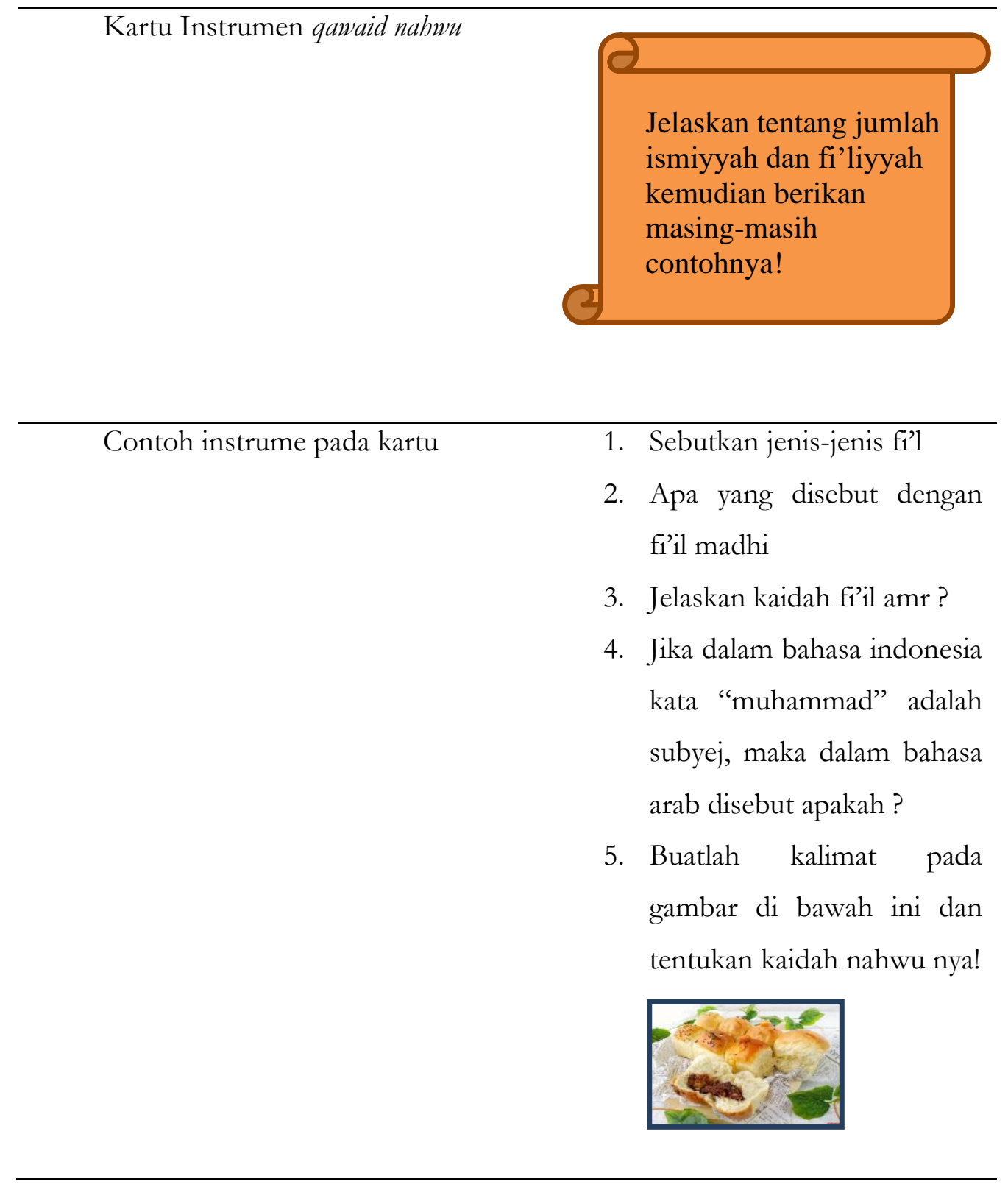

Melalui data yang sudah penulis dapatkan dari sini dapat menjawab permasalahan yang penulis telah rumuskan permasalahannya. Hadil dari pretest dan posttest akan dikupas dalam bentuk uraian dan data angka yang dihitung menggunakan data SPSS 16. Dari sini akan terlihat haisl dari pretest pemberian treatment dan posttest peserta didik. Sebelum dan sesudah menggunakan media Spining Wheel, hasil pembelajaran qawaid nahwu santriwati kelas VII Pondok Pesantren Darul Qur'an sebagai berikut:

Tabel 2. Data hasil pretest dan posttest

\begin{tabular}{clcc}
\hline NO & \multicolumn{1}{c}{ NAMA } & Pretest & Posttest \\
\hline 1. & Hidatatun Nik'mah & 58 & 78 \\
\hline 2. & Fitria Rahmadani Putri & 56 & 70 \\
\hline 3. & Nindia Hasanah Mubarok & 78 & 81 \\
\hline
\end{tabular}




\begin{tabular}{|c|c|c|}
\hline 4. $\quad$ Hafidzah Nur Al-Kindi & 56 & 78 \\
\hline 5. Nevana Salsabilla Rahma & 65 & 78 \\
\hline 6. Rifka Sa'adatul Maghfiroh & 68 & 78 \\
\hline 7. Widia Isnani & 70 & 90 \\
\hline 8. Izora Arkana Isnaini & 68 & 87 \\
\hline 9. Anita Novitasari & 68 & 85 \\
\hline 10. Zuhrotul Aini & 68 & 85 \\
\hline 11. Iftitah Ainur Rizka & 50 & 78 \\
\hline 12. Khoirulia Nur Safitri & 56 & 80 \\
\hline 13. Faizatun Ni'mah & 70 & 95 \\
\hline 14. Anisa Fatihatu sholihah & 56 & 87 \\
\hline 15. Rizka Amalia Yahya & 70 & 95 \\
\hline 16. Oktaviana Deva & 75 & 85 \\
\hline 17. Putri Febiola & 75 & 90 \\
\hline 18. Winda Novianti & 68 & 90 \\
\hline 19. Lailatul Husna & 68 & 78 \\
\hline 20. Vina Maghfirah Husada & 60 & 85 \\
\hline 21. Irma Maftuhah & 68 & 95 \\
\hline 22. Nurul Laili Ahmada & 60 & 80 \\
\hline 23. Fina Laelatul Barokah & 58 & 75 \\
\hline 24. Husna Nailul Muna & 60 & 85 \\
\hline 25. Alvita Nadira Hasanah & 50 & 75 \\
\hline 26. Firda Zakiyyatun Hasanah & 60 & 85 \\
\hline 27. Nurul Isnaini & 68 & 90 \\
\hline 28. Nurlita Cahyaningsih Astuti & 50 & 78 \\
\hline 29. Annisa Fatihati Muslihah & 70 & 95 \\
\hline 30. Aghnia Aisya Bahira & 56 & 75 \\
\hline Jumlah & 1.903 & 2.506 \\
\hline Rata-rata & 63.43 & 83.53 \\
\hline
\end{tabular}

Berdasarkan tabel yang telah penulis susun meunjukkan bahwa data nilai pretest dan posttest dapat dilihat peningkatan rata-rata nilai pretest dan posttest yaitu 63.43 menjadi 83.53. dari nilai rata-rata tersebut dapat dilihat adanya peningkatan rata-rata nilai sebesar $20.1 \%$. dari data di atas nilai hasil pembelajaran qawaid nahwu mengalami peningkatan secara signifikan.

Adapun rincian dari persyaratan pengujian analisis data akan dijelaskan sebagai berikut:

a. Uji Normalitas nilai Pretest dan posttest

Uji normalitas yang digunakan oleh peneliti ini guna mengetahui normal tidaknya distribusi sampel. Nilai yang digunakan untuk menguji normalitas adalah diambil dari nilai pretest dan posttest. Data bisa terbilang normal jika nilai signifikansi (sig) $>0.05$ dan data bisa terbilang tidak normal jika nilai signifikansi $(\mathrm{sig})<0.05$. berikut tabel output uji normalitas srebagai berikut: 
Tabel 3. Hasil normalitas data pretest dan posttest

\begin{tabular}{|l|l|l|l|}
\hline \multicolumn{4}{|l|}{ Tests of Normality } \\
\hline & Statistic & Df & Sig. \\
\hline Pretest & .931 & 30 & .052 \\
\hline Posttest & .950 & 30 & .165 \\
\hline
\end{tabular}

Berdasarkan uji normalitas menggunakan rumus saphiro wilk. Dari tabel di tas nilai signifikansi dapat dilihat dari masing-masing nilai pretest dan posttest memiliki nilai sig $>0,05$ jadi dapat disimpulkan bahwa nilai pretest dan posttest adalah normal.

b. Uji Homogenitas

Peneliti menggunakan uji homogenitas untuk mengetahui hasil sampel apakah bervarian homogen atau tidak. Untuk menguji homogenitas populasi penelitian dengan asumsi pengambilan keputusan data akan homogen jika nilai signifikansi $>0.05$ dan tidak homogen jika nilai signifikansi $<0.05$.

Tabel 4. Hasil uji homogenitas pretest dan posttest

\begin{tabular}{|l|l|l|l|}
\hline \multicolumn{2}{|l|}{ Test of Homogeneity of Variances } & \\
\hline \multicolumn{2}{|l|}{ Hasil belajar Qawaid Nahwu } & df2 & Sig. \\
\hline Levene Statistic & df1 & 58 & .287 \\
\hline 1.155 & 1 & & \\
\hline
\end{tabular}

Uji homogen di atas meggunakan one way anova. Berdasarkan data sail ouput pretest dan posttest kelas VII menunjukkan nilai signifikansi sebesar $0.287>0.05$. hal ini menunjukkan bahwa nilai homogen dan menunjukkan nilai yang signifikan. Artinya variansi nilai pretest dan posttest kelas VII keduanya homogen.

c. Uji Independent t Test

Pengambilan keputusan dalam uji independent $t$ Test ini adalah jika nilai t hitung $>\mathrm{t}$ tabel atau sig. ( 2 tailed) maka Ho ditolak. Tetapi jika t hitung $<\mathrm{t}$ tabel atau sig. ( 2 tailed), maka Ha diterima. 
Tabel 5. Hasil Uji Independent t Test Pretest-Posttest

\begin{tabular}{|c|c|c|c|c|c|}
\hline \multicolumn{6}{|l|}{ Group Statistics } \\
\hline & Kelas VII & $\mathrm{N}$ & Mean & Std. Deviation & Std. Error Mean \\
\hline belajar & Pretest & 30 & 63.43 & 7.758 & 1.416 \\
\hline Qawaid Nahwu & Posttest & 30 & 83.53 & 6.892 & 1.258 \\
\hline
\end{tabular}

Tabel 6. Hasil Uji Independent t Test Pretest-Posttest sig. 2 tailed

\begin{tabular}{|c|c|c|c|c|c|c|c|c|c|}
\hline \multicolumn{10}{|c|}{ Independent Samples Test } \\
\hline & \multirow[b]{2}{*}{$\mathrm{F}$} & \multirow[b]{2}{*}{ Sig. } & \multirow[b]{2}{*}{$\mathrm{T}$} & \multirow[b]{2}{*}{$\mathrm{df}$} & \multirow{2}{*}{$\begin{array}{l}\text { Sig. (2 } \\
\text { tailed) }\end{array}$} & \multirow{2}{*}{$\begin{array}{l}\text { Mean } \\
\text { Differe } \\
\text { nce }\end{array}$} & \multirow{2}{*}{$\begin{array}{l}\text { Std. Error } \\
\text { Difference }\end{array}$} & \multicolumn{2}{|c|}{$\begin{array}{l}95 \% \text { Confidence Interval of the } \\
\text { Difference }\end{array}$} \\
\hline & & & & & & & & Lower & Upper \\
\hline Hasil belajar & 1.155 & .287 & -10.609 & 58 & .000 & -20.100 & 1.895 & -23.892 & -16.308 \\
\hline $\begin{array}{l}\text { Qawald } \\
\text { Nahwu }\end{array}$ & & & -10.609 & 57.206 & .000 & -20.100 & 1.895 & -23.894 & -16.306 \\
\hline
\end{tabular}

Berdasarkan tabel di atas, dapat disimpulkan bahwa nilai pretest dan posttest kelas VII memiliki nilai yang signifikan. Dengan taraf signifikansi $0.000<0.05$ sehingga data dapat dikatan signifikan.

\section{Kesimpulan}

Berdasarkan hasil penelitian yang dilakukan di Pondok Pesantren, Wonosari, Gunungkidul, Yogyakarta pada santriwati kelas VII tahun pelajaran 2020/2021 maka telah diperoleh data sebagai berikut:

Pertama, Penggunaan media spinning wheel dapat meningkatkan dalam pembelajaran qawaid nahwn bagi santriwati kelas VII di Pondok Pesantren Darul Qur'an Wal Irsyad, Wonosari, Gunungkidul, Yogyakarta. Hal ini dapat dilihat dari hasil penilaian antara tes awal dan tes akhir terdapat peningkatan yang signifikan. Pada pretest siswa mendapat rata-rata nilai 63.43 sedangkan setelah dilakukan pretest yaitu melakukan posttest siswa mengalami peningkatan dengan mendapat nilai rata-rata 83.53

Kedua, Terdapat perbedaan nilai yang signifikan terhadap pembelajaran qawaid nabwu dan latihan soal sebelum menggunakan media spinning wheel dan sesudah menggunakan media spinning wheel bagi santriwati kelas VII Pondok Pesantren Darul Qur'an Wal Irsyad, Wonosari, Gunungkidul, Yogyakarta. hasil akhir ditunjukkan dengan uji independent t test yang memiliki nilai sigifikansi $0.000<0.05$ dengan dsasar keputusan Ha diterima. 
Ketiga, Dari sini dapat disimpulkan bahwa media spinning wheel dapat meningkatkan pembelajaran dan hasil belajar qawaid nahwu santriwati kelas VII Pondok Pesantren Darul Qur'an Wal Irsyad, Wonosari, Gunungkidul, Yogyakarta sebesar 20.1\%.

\section{Daftar Pustaka}

Abu Razin, Razin, and Razin Ummu Razin. "Ilmu Nahwu Untuk Pemula.” Pustaka Bisa, 2014. Amalah, Siti Fitri. "EFEKTIVITAS MEDIA PAPAN LIPAT UNTUK PENINGKATAN PENGUASAAN TATA BAHASA ARAB (MUBTADA KHABAR) DAN KETERAMPILAN MEMBACA SISWA KELAS VII MTs HASYIMIYAH KALISIDI UNGARAN." Universitas Negeri Semarang, 2017. https://docplayer.info/151793125Skripsi-untuk-memperoleh-gelar-sarjana-pendidikan.html.

Arikunto, Suharsimi. "Prosedur Penelitian Suatu Pendekatan Praktik. 2010." Jakarta: Rineka Cipta (2010).

Dabell, John. "Aktivitas Permainan Dan Ide Praktis Belajar Matematika." Jakarta: Erlangga (2009).

Devi, Riska Puspita. "PENINGKATAN HASIL BELAJAR BAHASA ARAB MELALUI METODE AL-QAWAID WA-TARJAMAH MENGGUNAKAN MEDIA VISUAL GAMBAR BAGI SISWA KELAS IV MIN KOLOMAYAN WONODADI BLITAR." Institut Agama Islam Negeri (IAIN) Tulungagung, 2014.

Ginnis, Paul. Trik Dan Taktik. Mengajar: Strategi Meningkatkan Pencapaian Pengajaran Di Kelas. Jakarta: PT Indexs, 2008.

Hakim, Arif Rahman. "Mempermudah Pembelajaran Ilmu Nahwu Pada Abad 20." Jurnal Al Maqayis 1, no. 1 (2014).

Hasyim, Mochamad, and Amang Fathurrohman. "Pengembangan Desain Permainan Stik Lalaran Untuk Peningkatan Kemampuan Mufrodat Dalam Kitab Bahasa Arab Ro'sun Sirah Bagi Santri Madrasah Diniyah Tingkat Ula." Studi Arab 9, no. 2 (2018): 147-160.

Nurdianto, Talqis. Ilmu Nahwu Bahasa Arab. Yogyakarta: Zahir Publishing, 2018.

Nurseto, Tejo. "Membuat Media Pembelajaran Yang Menarik.” Jurnal Ekonomi dan pendidikan 8, no. 1 (2011).

Prasetyo, Bambang, and Lina Miftahul Jannah. "Metode Penelitian Kuantitatif: Teori Dan Aplikasi, Jakarta, PT.” Raja Grafindo Persada (2006).

Zainal, Arifin. "Penelitian Pendidikan." Bandung: Rosda (2012). 
100 | Volume 11, Nomor 2, Desember 2020

Program Studi Pendidikan Bahasa Arab Universitas Yudharta Pasuruan https://jurnal.yudharta.ac.id/v2/index.php/studi-arab 